\title{
Development and Validation of a Semi-Structured Clinical Interview for Nightmare Disorder
}

\author{
Sooyeon Suh \\ Department of Psychology, Sungshin Women's University, Seoul, Korea \\ 악몽장애 선별을 위한 반구조화된 임상면담도구 개발 및 타당화 \\ 서수연 \\ 성신여자대학교 심리학과
}

Received February 5, 2021 Revised March 3, 2021 Accepted April 9, 2021

Address for correspondence Sooyeon Suh, PhD Department of Psychology, Sungshin Women's University, 2 Bomun-ro 34da-gil, Seongbuk-gu, Seoul 02844, Korea

Tel: $+82-2-920-7215$

Fax: +82-2-920-7215

E-mail: alysuh@sungshin.ac.kr
Objectives: Nightmare disorder is highly prevalent in clinical settings and is highly comorbid with posttraumatic stress disorder (PTSD). In the current study, we aimed to develop and validate a semi-structured interview based on the diagnostic criteria of the Diagnostic and Statistical Manual of Mental Disorders-fifth edition for diagnosing nightmare disorder. Methods: We developed a Semi-Structured Clinical Interview for Nightmare Disorder (SCIN) in five steps: we interviewed 100 females (mean age, 24.6 \pm 5.88 years) using the Clinician-Administered PTSD Scale for DSM-5 (CAPS-5); Structured Clinical Interview for DSM-IV Axis 1 Disorders, Research Version (SCID-I); and self-report questionnaires for nightmares (Disturbing Dream and Nightmare Severity Index, DDNSI), depression, state anxiety, trait anxiety, suicidal ideation, and insomnia. Two independent raters assessed the responses of the interviewees. The interrater reliability for the SCIN was calculated. Pearson's correlation coefficient was used to assess convergent validity between SCIN and the DDNSI. Chi-square analyses were conducted to compare prevalence of PTSD based on nightmare disorder diagnosis. Results: Among the participants, $42 \%$ were diagnosed with nightmare disorder, $15 \%$ had subthreshold nightmare disorder, and $43 \%$ did not have nightmare disorder. Interrater reliability was moderate (Kappa $=0.707, p<0.001)$. The semi-structured clinical interview showed good convergent validity with the DDNSI $(\mathrm{r}=0.639, p<0.001)$. Additionally, individuals who were identified as having nightmare disorder had higher levels of depression, state anxiety, trait anxiety, suicidal ideation, and insomnia $(p<0.001)$. Based on the PTSD diagnosis using CAPS-5, the nightmare group had a higher proportion of PTSD diagnoses than the no-nightmare group ( $26.2 \%$ vs. $8.6 \%$, respectively; $\left.\chi^{2}=38.41, p<0.001\right)$. Conclusions: The semi-structured clinical interview for nightmare disorder appears to have good reliability and validity and can be used in clinical settings.

J Sleep Med 2021;18(1):37-45

Key Words: Sleep, Parasomnias, Sleep wake disorders, Psychological interview, Nightmares.

\section{서 론}

악몽은 일반적으로 빠른 안구운동(rapid eye movement, $\mathrm{REM})$ 수면 단계에서 발생하며, 불쾌한 정서를 동반하고 즉 각적인 각성을 유발하는 꿈을 의미한다. 악몽은 각성을 유발 한다는 의미에서 '나쁜 꿈'과 구분되며, 깨어난 후에도 꿈이 생생하게 회상되며 빠르게 지남력을 회복하는 특성을 가지

This is an Open Access article distributed under the terms of the Creative Commons Attribution Non-Commercial License (https://creativecommons.org/licenses/by-nc/4.0) which permits unrestricted non-commercial use, distribution, and reproduction in any medium, provided the original work is properly cited.
고 있다. ${ }^{1,2}$

악몽은 빈도와 그로 인한 고통이 심해지면 악몽 장애(nightmare disorder)로 진단될 수 있으며, 현재 Diagnostic and Statistical Manual of Mental Disorders-fifth edition(DSM-5) 에서 수면-각성 장애로 분류되고 있다. ${ }^{3}$ 악몽 장애는 임상적 으로 의미가 있기 때문에 임상 장면에서의 체계적인 평가 및 치료가 필요하다. 악몽 장애는 일반 인구에서는 2 5\%의 유 병률이 추정되지만, 정신장애 표본에서는 유병률이 $29.9 \%$ 이 며, 그 중 외상후 스트레스 장애는 다른 정신장애에 비해 2.4 배로 높아 60 66\%의 유병률이 보고되고 있다.,5 악몽은 또한 
우울을 통제하고도 자살, 자해 행동, 해리 장애, 경계선 성격 장애와 같은 다른 정신병리와도 연관성이 있다. ${ }^{5}$ 이와 같이, 악몽 장애는 정신병리적 관점에서 평가하고 개입할 필요성 이 있다.

아직 임상 장면에서 악몽 장애를 체계적으로 평가할 수 있 는 타당화된 평가 도구가 부족하다. 현재 활용되고 있는 평가 도구로는, Spoormaker 등이 개발한 Diagnostic and Statistical Manual of Mental Disorders-fourth edition(DSM-IV) 을 기준으로 한 SLEEP-50의 자기보고식 질문지가 있는데, DSM-5의 새로운 진단기준이 반영되지 않았다. ${ }^{6} \mathrm{Krakow}$ 등 이 개발한 Disturbing Dreams and Nightmare Severity Index (DDNSI)는 자기 보고식 질문지로, 악몽에 대한 빈도와 고통 을 측정하지만 정확한 진단기준이 반영되지 않았으며, 자기 보고식 질문지라는 한계점이 있다. ${ }^{7}$ 반구조화된 면담도구는 자기보고식 질문지에 비해 임상가가 응답에서의 모순을 확 인하여 탐색할 수 있고, 비교적 신뢰로운 응답을 얻을 수 있 으며, 추가적으로 내담자의 응답 의미를 심층적으로 탐색할 수 있다는 이점이 있다. 또한, 수검자의 응답에 따라 문항을 개인에게 맞춤형으로 제공하여, 수검자에게 문항을 실시할 때 문항에 대한 이해를 증진시킬 수 있다. 구조화된 면담도 구는 임상 연구에서 정신장애를 평가하는 데 있어 황금기준 으로 간주되고 있다. 수면-각성 장애를 진단하는 데 있어 임 상 면담은 필수 사항이다. 수면 장애는 임상적 판단(clinical judgment)이 필요하기 때문에 자기보고식 질문지만으로는 수면의 다차원적인 특징을 이해하기는 불충분하다.

여러 선행결과를 바탕으로 악몽은 독립적인 수면 장애로 치료할 필요가 있으며, 낮과 밤 모두 기능 손상을 동반하기 때문에 임상 장면에서 개입할 필요성이 있다. 이에 따라 본 연구는 DSM-5 진단기준이 반영된, 임상가가 내담자와의 면 담 중에 직접 실시할 수 있는 구조화된 임상면담도구를 개발 하고 타당화하고자 하였다.

\section{방 법}

\section{연구 대상}

본 연구는 온라인 및 오프라인 홍보 게시물을 통해 연구 참 여자를 모집하였으며, 홍보물은 “악몽을 자주 꾸는 사람”과 “악몽을 자주 꾸지 않는 사람” 두 가지로 제작하여 악몽 장애 에 대한 가능성이 혼재된 일반인 연구참여자들을 모집하였 다. 본 연구는 연구에 자발적으로 참여를 희망한 성인 여성 100 명을 대상으로 실시하였다. 외상은 여성이 경험할 확률 이 남성에 비해 높고, 외상을 경험한 후에도 외상후 스트레스 장애가 발병할 확률이 남성에 비해 여성이 더 높다. ${ }^{8}$ 악몽 장
애 또한 여성이 남성에 비해 2 배의 유병률을 보이기 때문에 여성에 국한해 연구를 진행하였다. ${ }^{3}$

연구 참여 기준은 외상 사건 체크리스트(life events checklist for DSM-5)를 통해 외상 사건을 경험했다고 보고한 경 우들이었다. 제외 기준은 악몽 장애를 제외한 기타 주요 수면 장애를 진단 받았거나(불면 장애 제외) 수면에 영향을 주는 약물을 복용 중인 경우와 수면무호흡증, 렘수면 행동장애와 같은 수면 장애를 포함하였으며, 세코날, 바비튜레이트, 달마 돔, 할시온과 같은 안정제 및 수면제 계열 약물 및 비처방 수 면제 등의 약물을 복용한 사람도 연구에서 제외하였다. 연구 대상자 선별을 위해 일차적으로 온라인 질문지를 이용하여 연구 참여 동의 및 개인 정보, 악몽을 포함한 수면 관련 질문 지에 응답하여 스크리닝 과정을 통해 선발하였다. 이후, 최종 선정된 연구 대상자는 DSM-IV의 제I축 장애의 구조화된 임 상적 면담 연구자용(Structured Clinical Interview for DSMIV Axis 1 Disorders, Research Version; SCID-I)에서 정신증 및 알코올/기타물질장애에 대해서도 확인하였다. 모든 연구 참여자들은 개발된 악몽 장애 진단을 위한 반구조화된 임상 면담을 진행하였고, Clinician-Administered PTSD Scale for DSM-5(CAPS-5)를 통해 Posttraumatic Stress Disorder (PTSD) 진단 여부를 확인하였다. 총 면담은 $1.5 \sim 2$ 시간 정도 소요되었다.

본 연구는 성신여자대학교 기관생명윤리위원회(Institutional Review Board, IRB)의 승인을 받았다(IRB 승인번호: SSWUIRB-2019-034).

\section{측정 도구}

악몽 심각도 척도(Disturbing Dreams and Nightmare Severity Index, DDNSI)

악몽 심각도를 평가하기 위해 Krakow 등이 개발하고 Lee 등이 한국판으로 타당화한 악몽의 고통 및 빈도를 측정하는 DDNSI 질문지를 사용하였다. ${ }^{79}$ 질문지의 문항들은 악몽 빈 도를 측정하기 위해 일주일에 한 번, 한 달에 한 번과 같이 “악몽을 꾼 날”과 “하룻밤 동안 악몽을 꾼 횟수”에 대한 두 문항, 악몽으로 인한 각성 여부, 악몽 문제의 심각도, 악몽의 강도에 대해 평가하는 세 문항을 합하여 총 다섯 문항으로 이 루어져 있다. 악몽 심각도 점수는 다섯 문항을 합산하여 산 출하며, 총점은 0 37점으로 10점 이상인 경우 악몽 장애 진 단에 일치하는 것으로 간주한다. ${ }^{10}$ 국내 타당화 논문의 내적 일치도는 0.92 로 나타났다. ${ }^{9}$ 
악몽으로 인한 기능 손상 척도(Nightmare Effects Survey, NES)

악몽으로 인한 기능 손상 척도는 Krakow 등이 개발한 자 기보고식 질문지이다. ${ }^{11}$ 총 10 문항으로 구성되어 있으며, 수 면과 관련한 4가지 문항, 기분상태, 정신 및 신체건강, 사회적 활동, 학업 및 직무, 인관 관계에 대한 악몽의 부정적 영향을 각각 한 문항씩으로 구성된 질문지를 사용하였다. 점수가 높 을수록 악몽으로 인한 기능적 손상 정도가 심각한 것으로 간 주한다.

불면증 심각도 척도(Insomnia Severity Index, ISI)

불면 증상의 심각도를 평가하기 위해 Bastien 등이 개발하 고 $\mathrm{Cho}$ 등이 한국판으로 타당화한 한국판 불면증 심각성 척 도를 사용하였다. ${ }^{12,13}$ 총 7문항으로 구성되어 있으며 불면증 이 심한 정도, 수면 양상에 대한 만족도, 수면 문제로 인한 주간의 기능 손상 등과 같은 불면증과 관련된 증상을 평가 한다. 최근 2주간의 증상을 5점 리커트 척도로 평정하며, 총 점은 0 28점이다. 점수가 높을수록 불면증 심각도 수준이 심각하다고 간주하여, 총 문항 합산 점수를 기준으로 10점 이상일 경우 임상적 불면증으로 간주한다. 국내 불면증 심각 도 척도의 내적 일치도는 0.92 로 나타났다. ${ }^{13}$

\section{자살 심각도 척도(Depressive Symptom Inventory-}

Suicidality Subscale, DSI-SS)

자살사고 수준을 측정하기 위해 Metalsky와 Joiner가 개발 한 Hopelessness Depression Symptom Questionnaire 중 '자 살에 대한 생각' 4문항을 Suh 등이 타당화 한 한국판 척도를 사용하였다. ${ }^{14,15}$ 최근 2 주간의 자살사고를 평가하며, 각 문항 은 4점 리커트 척도로 평정한다. 총점은 0 12점으로 점수가 높을수록 자살 사고 수준이 높다는 것을 의미하며, 4점 이상 일 경우 위험군으로 간주한다. 국내 타당화 논문의 내적 일 치도는 0.93 으로 나타났다. ${ }^{15}$

\section{한국판 역학연구 우울척도(The Center for}

\section{Epidemiologic Studies Depression Scale, CES-D)}

우울 증상을 측정하기 위해 Radloff가 개발하고 Chon 등 이 국내 실정에 맞게 타당화한 한국판 척도를 사용하였다. ${ }^{16,17}$ 최근 일주일 동안의 우울증상을 측정하며, 총 20문항으로 우 울정서 관련 7문항, 대인관계 관련 2문항, 긍정적 정서 관련 4문항, 신체적 저하 관련 7문항으로 구성되어 있으며, 긍정적 정서 관련 문항의 경우 역환산 처리하여 점수를 합산한다. 총점은 0 60점으로 21점 이상이면 우울이 있다고 간주한다. 국내 타당화 논문의 내적 일치도는 0.91로 나타났다. ${ }^{17}$
상태 불안 척도(State-Trait Anxiety Inventory, STAI-S)

불안 상태를 측정하기 위해 Spielberger 등이 개발하고 Kim 등이 표준화한 상태 불안 척도를 사용하였다. ${ }^{18,19}$ 특수한 상 황에서 그 상황을 어떻게 느끼는지를 묻는 20 개 문항으로 구 성되어 있으며, 각 문항의 점수를 합산하여 총점을 구한다. 총점 20 80점으로 점수가 높을수록 상태 불안 정도가 높은 것으로 간주한다. 국내 타당화 논문의 내적 일치도는 0.91 로 나타났다. ${ }^{19}$

\section{특성 불안 척도(State-Trait Anxiety Inventory, STAI-T)}

불안에 대한 개인적 차이를 알아보기 위해 Spielberger 등 이 개발하고 $\mathrm{Kim}$ 등이 표준화한 특성 불안 척도를 사용하였 다. 18,19 한 개인이 지니고 있는 개인적인 불안에 대한 특성을 물어보는 20개 문항으로 구성되어 있으며, 각 문항별 점수를 합산하여 총점을 구한다. 총점 20 80점으로 점수가 높을수 록 특성 불안 정도가 높은 것으로 간주한다. 국내 타당화 논 문의 내적 일치도는 0.93 으로 나타났다. ${ }^{19}$

엡워스 졸음 척도(Epworth Sleepiness Scale, ESS)

본 연구 참여자의 주간 졸림 수준을 평가하기 위해 Johns 가 개발하고 Cho 등이 한국판으로 타당화한 척도를 사용하 였다. 20,21 총점 0 24점으로 점수가 높을수록 주간 졸림으로 인한 기능 손상이 높은 것으로 간주한다. 국내 타당화 논문 의 내적 일치도는 0.90 으로 나타났다. ${ }^{21}$

\section{$\mathrm{DSM}-\mathrm{IV}$ 의 제I축 장애의 구조화된 임상적 면담 연구자용}

(Structured Clinical Interview for DSM-IV Axis 1

Disorders, Research Version, SCID-I)

본 연구에서는 Hahn 등이 개발한 한국판 SCID-I을 이용 하여, 연구 참가자들의 정신증과 알코올 및 기타 물질 사용 장애 여부에 대해 살펴보았다. SCID-I는 반구조화된 면담도 구로 DSM-IV 진단 기준에 따라 축1질환을 신뢰성 높게 진 단 내리기 위해 사용되며, 임상가들이 짧은 시간 내에 진단 평가가 이루어지도록 개발되었다. 현재 다양한 국가의 언어 로 번역되어 전세계적으로 진단 평가하는데 있어 표준적인 방법으로 사용되고 있다. 또한, 정신질환 진단 분류 및 기준 에 익숙한 전문가들에 의해 시행되는 면담도구로 진단 기준 문항에 관한 평가를 진행하여, 면담자가 진단 기준에 맞는지 에 대해 임상적 판단을 내리고 요약 채점표를 이용하여 원 활한 평가를 진행한다. 본 연구에서는 정신증 여부와 물질/ 알코올 사용 장애 여부를 확인하기 위해 사용되었다. 한국판 
SCID-I 개발을 위해 각 질환의 면담자간 신뢰도를 확인하 여 신뢰도 연구를 진행한 결과 대부분의 정신질환에 있어 0.07 이상의 높은 Kappa 값을 보였다. ${ }^{22}$

\section{DSM-5용 임상가를 위한 외상후 스트레스장애 척도 (Clinician-Administered PTSD Scale for DSM-5, CAPS-5)}

본 연구 참가자들의 PTSD 진단 여부를 확인하기 위해 DSM-5 진단 기준에 맞춰 개정된 CAPS-5를 사용하였다. ${ }^{23}$ CAPS-5는 PTSD를 진단하기 위해 가장 널리 사용되는 구조 화된 면담도구로 DSM-5에 기술된 PTSD 진단 기준을 모두 포함하여 면담이 구성되어 있다. 본 연구에서는 원문 CAPS-5 매뉴얼을 원어와 한국어를 원활히 사용하는 임상심리전문가 가 번안하여 사용하였다. ${ }^{24}$

\section{연구 절차}

\section{면담 도구 개발}

질문지 개발은 $\mathrm{DeVellis}$ 가 제시한 절차를 착안하여 총 5 단 계로 진행하였다. ${ }^{25}$ 첫 단계는 '사용 목적 설정하기' 단계로, DSM-5에 대한 이해도가 있는 정신건강 전문가를 주 사용자 로 선정하였고, 악몽 장애를 진단하기 위한 사용 용도를 결 정하였다. 두번째 단계는 '문항 구성' 단계로, DSM-5 진단 기준을 근거로 변인 추출을 하여 문항을 구성하였다. 세 번 째 단계는 '형식 결정' 단계로, 정신장애를 진단하는데 가장 흔히 사용되는 반구조화된 면담도구인 Structured Clinical Interview for DSM-IV, non-patient version(SCID-NP)을 참고하였다. ${ }^{26}$ 본 연구의 면담도구에서 진단기준 문항의 경우, 1(해당 안됨), 2(역치하), 3(역치 이상)으로 채점되며, 채점하 기에 불충분한 정보는 물음표(?)로 채점하였다. 또한, 추가 적인 악몽 장애 증상에 대한 문항 중, 지속 기간은 급성(1개 월 이하), 아급성(1개월 초과 6개월 미만), 지속성(6개월 이 상)으로 구성하였으며, 악몽 장애의 심각도 및 빈도는 경도 (평균 주 1회 미만), 중등도(주 1회 이상이지만 매일 발생하 지는 않음), 고도(매일 밤마다 발생)로 설정하였다. 강도의 경우, 내담자가 보고한 주관적 고통에 따라 검사자가 매우 낮음, 분명히 존재함, 현저함, 극심함으로 채점할 수 있도록 척도를 구성하였다. 이를 통해 최종적으로 악몽 장애 진단은 1(해당 안됨)과 2(해당됨)로 평가하며, 역치하인 경우 1(해당 안됨)로 평가하도록 하였다. 네번째 단계는 '도구 검토' 단계 로, DSM-5에 대한 이해가 충분한 임상심리전문가가 예비 로 고안된 면담도구에 대한 검토를 전문가들과 함께 진행하 여, 면담도구가 적절하게 구성되어 있는지 등의 내용 타당도
를 검증하는 과정을 거쳤다. 또한, 해당 전문가 Focus Group Interview를 통해 임상에서 사용하는 표현들을 문항에 적용 하였다. 마지막 단계는 '사전 검사' 단계로, 면담 도구 개발에 관련이 없는 일반인에게 실시하여 문항에 대한 이해도를 평 가하고 어색한 문구를 수정하여 최종안에 도달하였다.

주요 문항은 DSM-5 진단기준을 토대로 구성되었으며, 추 가적으로 악몽 지속 기간, 악몽 빈도, 주관적 고통 항목을 포 함하여 악몽 증상에 대한 자세한 정보를 제공하고자 하였다. 문항은 총 10 문항으로 구성되었으며, 문항 1 7은 DSM-5의 진단기준 5 개를 반영하였고, 지속 기간, 심각도와 빈도, 그리 고 강도에 대한 3 문항이 추가되었다. 면담을 통해 얻은 정보 들을 바탕으로 모든 문항이 3(역치 또는 해당됨)으로 채점되 는 경우 악몽 장애에 해당되는 것으로 결과를 나타내게 된 다[면담 도구 내용은 Supplementary Materials(in the online-only Data Supplement) 참고].

\section{면담도구 실시를 위한 면담원 교육}

최종적으로 개발된 면담도구의 원활한 사용을 위해 면담 원 교육을 진행하였다. 면담원 교육 과정은 다음과 같다. 먼 저, 악몽에 대한 문헌자료를 통해 악몽 장애의 진단 기준 및 특성, 임상적 양상에 대한 학습을 진행하였다. 또한, SCID-I 에서의 면담 방법 및 채점 방식 등에 대한 교육을 진행하였 다. 이후, DSM-5에 대해 깊이 이해하고 있는 임상심리전문 가가 내담자를 대상으로 악몽 장애 진단을 위한 반구조화된 임상적 면담을 참관하여 내담자에 맞춰 질문하는 방법과 중 요한 정보를 파악하는 방법 등에 대해 배우는 시간을 가졌다. 다음으로, 정신병리 사례를 활용하여 역할극 시연을 통해 면 담 진행 및 채점 등에 대해 익히는 시간을 가졌다. 본 시연을 통해 진행된 면담은 임상심리전문가에게 지도 및 감독을 받 았으며, 이러한 과정을 수차례 반복한 후 실제 면담에 투입 되었다. 실제 면담 투입 이후에도 지속적으로 임상심리전문 가의 지도 및 감독을 받았다.

\section{표본 추출}

본 연구는 홍보를 통해 모집된 사람들에게 연구 동의서를 작성하게 한 후 개인정보 및 악몽과 수면에 관련된 질문지를 포함한 온라인 설문지를 진행하였다. 온라인 설문지에 참여 한 사람들을 DDNSI 임상 절단점을 기준으로, 잠재적 악몽 군 및 정상군을 분류하여 각각 랜덤하게 표본을 추출하여 최종 연구 대상자를 선정하였다.

\section{분석 방법}

분석 방법으로는, 면담을 통해 수집한 정보들을 바탕으로 
SPSS 21.0 버전(IBM Corp., Armonk, NY, USA)을 사용하 였다. 먼저, 인구통계학적 특성과 자기보고식 질문지 점수들 을 살펴보기 위해 기술통계를 실시하였고, 면담 도구의 수렴 타당도를 확인하기 위해 기존의 악몽장애 척도(DDNSI)를 통해 구분된 악몽군과 비악몽군을 활용하여 Pearson 상관 분석을 실시하였다. 또한, 훈련 받은 독립된 검사자들의 분 산을 확인하고자 100 명의 연구 대상자 중 56 명의 면담 녹취 록을 통해 2차 채점을 진행하였다. 이후, Kappa 계수를 통해 본 면담의 신뢰도를 검증하였다. Kappa 계수는 두 검사자 간의 합의한 정도를 측정하는 계수이며, 우연으로 서로 합의 했을 가능성을 수정해주기 때문에 악몽 장애와 같이 유병률 이 낮은 진단에서 두 검사자 간의 일치율이 우연으로 합의 했을 가능성을 고려하여 보수적으로 도출된다는 이점이 있 다. 27,28 이후, 범주별 사례 수가 30 이상인 경우, 중심극한정 리에 따라 정규 분포로 간주하여 면담을 통해 구분된 집단들 의 차이를 살펴보고자 t-test를 사용하고, 빈도 분석 및 범주 형 변수의 상관을 확인하고자 카이제곱 검정을 사용하였다.

\section{결 과}

\section{인구통계학적 특성 및 임상 지표}

본 연구는 성인 여성 중 외상을 경험하고 악몽 장애 진단이 가능한 여성 100 명을 대상으로 분석하였다. 외상을 경험한 악몽 장애 환자군과 정상군의 인구통계학적 자료를 분석한 결과는 Table 1에 제시하였다. 연구 참여자들의 평균 연령은 24.6( \pm 5.88$)$ 세였으며, 20대 연령 집단 비율이 가장 빈도가 높 았고(75.0\%), 결혼 상태는 미혼이 가장 빈도가 높았다(86.0\%). 교육 수준은 대학 재학의 비율이 가장 높았다(53.0\%).

\section{악몽 특성}

그 결과, 연구참여자들의 DDNSI의 평균 점수는 $10.74( \pm$ 8.69)였으며, 이 중 $61 \%(\mathrm{n}=61)$ 가 10점 이상으로 악몽 장애로 분류되었다. 개발된 임상면담도구(Semi-Structured Clinical Interview for Nightmare Disorder, SCIN)을 통해 42\%(n=42) 가 악몽 장애에 해당되었으며, $15 \%(\mathrm{n}=15)$ 가 역치하 악몽 장 애, $43 \%(\mathrm{n}=43)$ 가 비악몽군으로 분류되었다. $\mathrm{SCIN}$ 을 통해 악몽 장애로 분류된 42명 중 41명이 DDNSI에서도 임상 절 단점인 10 점 이상을 보고하여 $97.6 \%$ 의 일치율을 보였다.

악몽 장애에 해당되는 참여자들 중에는 악몽의 지속 기간 이 6개월 이상이라고 보고한 경우가 $95.2 \%$ 였으며, 빈도는 주 1 회 이상 발생하지만 매일 발생하지 않는 경우가 $66.7 \%$ 였다. 악몽으로 인한 주관적 고통에 대한 문항에 대해서는 과반수 이상(52.4\%)이 악몽으로 인한 현저한 고통을 느낀다
고 응답했다.

\section{검사자간 신뢰도}

1 차 면담을 통해 도출한 진단(악몽 장애 있음/없음)에 대 해서는 면담 내용을 녹음하였다. 표본 중 56 명을 추출하여 다른 연구원이 녹음파일을 듣고 독립적으로 채점을 진행해 서 검사자간 신뢰도를 도출했다. 100 명을 대상으로 한 1차 채점과 2 차 채점 간의 교차 분석을 한 결과, Kappa 계수는 0.707 $p<0.001)$ 로 Cohen이 제시한 기준에서 moderate 정도 였다. 27,28

\section{반구조화된 악몽 장애 면담 도구와 악몽 심각도 척도의 수렴 타당도}

악몽군 100 명을 대상으로 반구조화된 악몽 장애 면담도구 의 수렴 타당도를 검증하기 위해 악몽으로 인한 기능 손상을 측정하는 또 다른 악몽 질문지인 DDNSI 간의 Pearson 상관 분석을 실시했다. 반구조화된 악몽 장애 면담 도구에서 분류 된 집단(악몽군/비악몽군)과 DDNSI 총점( $\mathrm{r}=0.639, p<0.001)$ 간에는 유의한 정적 상관이 있었다.

\section{악몽군과 비악몽군 비교}

본 면담 도구로 산출한 악몽군과 비악몽군의 임상적 차이 를 Table 2에 제시하였다. 총 피험자 100명 중 6명이 질문지 수집에 오류가 있어 총 94명의 데이터로 분석을 진행하였다. 악몽군으로 분류된 참여자들은 비악몽군에 비해 우울, 상태 불안, 특성불안, 자살 경향성과 불면증 모두 유의미하게 높 게 나왔다 $(p<0.001)$.

\section{악몽군과 비악몽군의 PTSD}

개발된 면담 도구를 통해 분류된 악몽군과 비악몽군의 PTSD 여부를 CAPS -5 를 통해 확인하였다(Table 3). 악몽군 은 비악몽군에 비해 PTSD 진단이 가능한 비율이 차이가 컸 다(26.2\% vs. 8.6\%). 역치하 PTSD의 경우도 악몽군이 비악 몽군에 비해 현저하게 비율이 높았다(41.5\% vs. $1.7 \%$ ). 악몽 여부에 따른 PTSD 진단 여부를 교차분석한 결과 차이는 유 의미했다 $\left(\chi^{2}=38.414, p<0.001\right)$. 본 연구에서 사용된 역치하 악몽 장애는 반구조화된 면담도구를 통해 진단 기준 $\mathrm{A}$ 는 3(역치 또는 해당됨)으로 채점되었으나 나머지 진단 기준에 있어 2(역치 미만) 및 1 (해당 안 됨) 하나라도 채점되는 경우 를 의미한다. 
Table 1. Demographic information $(n=100)$

\begin{tabular}{|c|c|c|c|}
\hline & Total $(n=100)$ & Nightmare group $(n=42)$ & Non-nightmare group $(\mathrm{n}=58)$ \\
\hline Age (years) & $24.6 \pm 5.88$ & $25.1 \pm 6.45$ & $24.3 \pm 5.48$ \\
\hline $10 \mathrm{~s}$ & $8(8.0)$ & $6(14.3)$ & $2(3.4)$ \\
\hline $20 \mathrm{~s}$ & $75(75.0)$ & $27(64.3)$ & $48(82.8)$ \\
\hline $30 \mathrm{~s}$ & $14(14.0)$ & $7(16.7)$ & $7(12.1)$ \\
\hline $40 \mathrm{~s}$ & $3(3.0)$ & $2(4.8)$ & $1(1.7)$ \\
\hline \multicolumn{4}{|l|}{ Marital status } \\
\hline Single & $86(86.0)$ & $35(83.3)$ & $51(12.1)$ \\
\hline Married/domestic partnership & $13(13.0)$ & $6(14.3)$ & $7(87.9)$ \\
\hline Missing & $1(1.0)$ & $1(2.4)$ & $0(0.0)$ \\
\hline \multicolumn{4}{|l|}{ Education level } \\
\hline High school graduate & $4(4.0)$ & $4(9.5)$ & $0(0.0)$ \\
\hline Some college & $53(53.0)$ & $18(42.9)$ & $35(60.3)$ \\
\hline Associate degree & $5(5.0)$ & $4(9.5)$ & $1(1.7)$ \\
\hline Bachelor's degree & $27(27.0)$ & $11(26.2)$ & $16(27.6)$ \\
\hline Advanced degree or above & $11(11.0)$ & $5(11.9)$ & $6(10.3)$ \\
\hline \multicolumn{4}{|l|}{ Clinical indices } \\
\hline DDNSI & $10.74 \pm 8.69$ & $17.95 \pm 5.12$ & $5.52 \pm 6.81$ \\
\hline NES & $13.49 \pm 7.02$ & $16.14 \pm 6.59$ & $9.04 \pm 5.33$ \\
\hline ESS & $8.33 \pm 3.78$ & $9.31 \pm 3.84$ & $7.62 \pm 3.61$ \\
\hline CES-D & $23.69 \pm 12.85$ & $32.30 \pm 10.98$ & $17.31 \pm 10.20$ \\
\hline STAI-S & $50.88 \pm 12.50$ & $60.35 \pm 8.99$ & $43.87 \pm 9.84$ \\
\hline STAI-T & $51.85 \pm 12.22$ & $60.60 \pm 9.94$ & $45.37 \pm 9.43$ \\
\hline DSI-SS & $2.51 \pm 2.72$ & $4.08 \pm 2.89$ & $1.35 \pm 1.90$ \\
\hline ISI & $14.68 \pm 7.04$ & $19.20 \pm 4.92$ & $11.33 \pm 6.50$ \\
\hline \multicolumn{4}{|l|}{ Semi-Structured Interviews } \\
\hline Psychosis (SCID-I) & $6(6.0)$ & $5(11.9)$ & $1(1.7)$ \\
\hline Substance use disorder (SCID-I) & $6(6.0)$ & $4(9.5)$ & $2(3.4)$ \\
\hline Past Substance use disorder (SCID-I) & $9(9.0)$ & $5(11.9)$ & $4(6.9)$ \\
\hline PTSD (CAPS-5) & $16(16.0)$ & $11(26.2)$ & $5(8.6)$ \\
\hline
\end{tabular}

Data are presented as mean \pm standard deviation or n (\%). DDNSI: Disturbing Dreams and Night-mare Severity Index, NES: Nightmare Effects Survey, ESS: Epworth Sleepiness Scale, CES-D: Center for Epidemiologic Studies-Depression Scale, STAI-S: State-Trait Anxiety Inventory-State, STAI-T: State-Trait Anxiety Inventory-Trait, DSI-SS: Depressive Symptom Inventory-Suicidality Subscale, ISI: Insomnia Severity Index, SCID-I: Structured Clinical Interview for DSM-IV Axis 1 Disorders, Research Version, CAPS-5: Clinician-Administered PTSD Scale for DSM-5

\section{고 찰}

본 연구는 DSM-5에 근거한 악몽 장애 진단을 위한 반구 조화된 임상면담도구를 개발하고 타당도를 검증하였다. 악 몽을 꾸는 연구 참여자들을 모집한 결과, 그 중 $42 \%$ 가 악몽 장애에 해당됐으며, 주 1 회 이상 악몽을 꾸고, 악몽으로 인해 현저한 고통을 경험하고 있다고 응답한 사람들이 과반수 이 상이었다. 이처럼 악몽은 불면증과 독립적인 수면 장애이며, 주간과 야간 모두 심각한 기능 손상의 원인이 될 수 있기 때 문에 체계적으로 평가하고 개입해야 할 필요성을 다시 확인
할 수 있었다. ${ }^{29}$ 본 연구에서 개발한 악몽 장애 진단을 위한 반구조화된 임상면담도구는 임상가가 환자에게 쉽게 활용 할 수 있는 반구조화된 면담도구이며, 국내외로 임상가가 활 용할 수 있는 악몽 장애 진단을 위한 면담도구는 국내외 최 초로 개발되고 타당화되었다.

악몽 장애 진단을 위한 반구조화된 면담 도구를 사용하여 선별된 악몽 장애 집단은, 기존에 많이 사용되던 악몽을 평 가하기 위한 자기보고식 질문지인 DDNSI를 통해 구분한 집 단과의 상관이 유의하였다. 이는 악몽 장애 진단을 위한 반 구조화된 임상면담도구가 타당하게 악몽 장애를 진단할 수 
Table 2. Clinical differences of the nightmare group compared to the non-nightmare group

\begin{tabular}{lccc}
\hline & $\begin{array}{c}\text { Non-nightmare group } \\
(\mathrm{n}=54)\end{array}$ & $\begin{array}{c}\text { Nightmare group } \\
(\mathrm{n}=40)\end{array}$ & \multirow{2}{*}{$p$} \\
\cline { 2 - 3 } & $\mathrm{M}(\mathrm{SD})$ & $\mathrm{M}(\mathrm{SD})$ & \\
\hline CES-D & $17.31(10.20)$ & $32.30(10.98)$ & $<0.001^{*}$ \\
STAI-S & $43.87(9.84)$ & $60.35(8.99)$ & $<0.001^{*}$ \\
STAI-T & $45.37(9.43)$ & $60.60(9.94)$ & $<0.001^{*}$ \\
DSI-SS & $1.35(1.90)$ & $4.08(2.89)$ & $<0.001^{*}$ \\
ISI & $11.33(6.50)$ & $19.20(4.92)$ & $<0.001^{*}$ \\
\hline
\end{tabular}

${ }^{*} p<0.001$. CES-D: Center for Epidemiologic Studies-Depression Scale, STAI-S: State-Trait Anxiety Inventory-State, STAI-T: StateTrait Anxiety Inventory-Trait, DSI-SS: Depressive Symptom Inventory-Suicidality Subscale, ISI: Insomnia Severity Index

있음을 의미하며, 개발된 면담도구가 높은 수렴타당도를 가 진다고 볼 수 있다. 또한, 독립된 검사자 두명이 악몽 장애를 위한 반구조화된 임상면담도구를 통해 moderate 수준(Kap$\mathrm{pa}=0.707)$ 의 정도로 검사자간 신뢰도를 확인하였다. 이는 악 몽 장애 진단을 위한 반구조화된 임상면담도구가 검사자 개 인간의 차이에 영향을 받지 않고 일관성 있게 악몽 장애를 진단할 수 있는 신뢰로운 평가도구라는 것을 증명한다.

본 연구에서 악몽군은 비악몽군에 비해 우울, 특성 및 상태 불안, 자살 경향성이 유의미하게 높았다. 이는 악몽이 여러 정신병리와 관련이 있다는 선행 연구와 일치한다. 악몽은 우 울, 불안과 관련이 있을 뿐만 아니라 자살에 대한 위험성을 증가시킨다는 선행 연구와 일치한다. 1,930 그 이외에도 악몽은 정신증적 증상, 조현 스펙트럼 장애, 양극성 장애, 경계선 성 격 장애, 신경증 등의 정신장애와도 유의미한 관련이 있는 것 으로 선행 연구에서 보고되었다. 이와 같이 악몽은 공병 질 환과 독립적으로 다양한 정신 장애의 위험성을 증가시키는 것으로 알려져 있기 때문에 임상 장면에서 중요하게 스크리 닝을 해야 하는 증상이다. 31,32

연구 결과, 악몽군은 비악몽군에 비해 불면증 점수도 유의 미하게 높았다. 반복되는 악몽으로 인해 불면증과 같은 수면 장애가 유발될 수 있다. 악몽은 주로 REM 단계에서 경험하 게 되며, 각성을 유발하며 빠른 지남력을 회복하게 되는 특 성이 있어, 입면 후 각성시간을 증가시키고 다시 잠드는 것을 어렵게 만들 수 있다. 또한, 악몽은 공포, 불안, 슬픔과 같은 불쾌한 감정을 동반하기 때문에, 악몽장애 환자들은 취침 시 간을 회피하며 수면 개시에 대한 어려움을 경험할 수 있다. ${ }^{33-35}$ 선행 연구에서 악몽은 수면 개시의 어려움, 유지의 어려움, 조 기 기상과 같은 수면 문제를 경험하게 되어 주간 기능에 고통 이나 손상을 경험할 수 있다고 보고하였다. ${ }^{36}$

본 연구에서 개발된 반구조화된 임상면담도구를 통해 진
Table 3. Nightmare groups based on PTSD diagnosis

\begin{tabular}{lcccc}
\hline & \multicolumn{3}{c}{ PTSD group } & \multirow{2}{*}{$\chi^{2}$} \\
\cline { 2 - 4 } & Non-PTSD & $\begin{array}{c}\text { Subthreshold } \\
\text { PTSD }\end{array}$ & PTSD & \\
\hline Nightmare group & & & 3 & \\
Non-nightmare & 39 & 1 & 2 & \\
Subthreshold & 13 & 0 & 11 \\
nightmare & & 17 & 11 \\
Nightmare & 13 & & & \\
disorder & & & & \\
\hline
\end{tabular}

${ }^{*} p<0.001$. PTSD: Posttraumatic Stress Disorder

단된 악몽 장애 여부에 따른 PTSD 진단 여부는 유의미했다. 악몽군은 비악몽군에 비해 PTSD 진단이 가능한 비율이 차 이가 컸다(26.2\% vs. $8.6 \%)$. 이는 선행연구에서 악몽 장애와 $\mathrm{PTSD}$ 의 높은 공병율과 일치하는 결과이다. ${ }^{37}$ 또한, 외상 직 후에 악몽을 많이 꾸는 사람들은 외상 이후 PTSD 발병률이 2.9 배 증가, 증상도 비악몽군에 비해 더 심각하다는 연구를 고려할 때, 외상을 경험한 환자들의 악몽 증상을 임상적으로 의미있게 볼 필요가 있다는 것도 시사한다. ${ }^{738,39}$ 외상을 경험 하게 되면, 그 이후 꿈을 통해 외상 사건을 기존 기억체계에 통합하기 위한 시도를 하며, 악몽을 통해 재경험 증상이 나 타난다. ${ }^{40}$ 그렇지만 외상 경험에 대한 인지적 통합이나 정서 처리가 실패하면, 외상 사건의 재경험, 심리적 고통을 피하기 위한 회피와 부인 증상이 나타나며, 결과적으로 외상 관련 기억 및 정서는 억압되어 처리되지 못하지만, 의식을 침투하 는 악몽과 침습적 증상들이 발생하여 결국 PTSD로 이어지 게 된다. ${ }^{41,42}$ 악몽에 대한 개입 만으로도 PTSD 증상이 완화 될 수 있다는 선행 연구도, 악몽이 PTSD의 핵심 증상이라는 점을 강조한 연구들을 고려할 때, 타 장애에 비해 PTSD 환 자들은 악몽에 대한 체계적 평가와 개입이 이루어지는 것이 중요하다. ${ }^{43,44}$

본 연구의 제한점은 다음과 같다. 첫째, 본 연구 대상자는 대부분 젊은 여성으로 국한해 모집하였다. 이는 전체 인구로 일반화하는데 어려움이 있으므로 추후 연구에서는 남성, 그 리고 다양한 연령층을 대상으로 모집하여 재검증을 통해 성 별의 차이가 있을지에 대해 살펴볼 필요가 있다. 둘째, 그 외 에 검사-재검사 신뢰도가 실시되지 않아 시간에 따른 안정성 을 보장할 수 없고, 추후 반복 측정을 통해 관찰자내 신뢰도 를 확인할 필요가 있다. 셋째, 본 연구는 일반인을 대상으로 했기 때문에 임상현장에서의 유용성에 대한 결론을 내리기 에는 한계가 있다. 향후 임상집단에 적용하여 본 연구에서 개 발한 반구조화된 임상면담도구의 예측 타당도와 함께 기타 타당도도 연구할 필요가 있다. 
그럼에도 불구하고 본 연구에서 개발한 악몽장애를 위한 반구조화된 임상면담도구는 임상 장면에서 중요한 문제로 대두되고 있는 악몽 장애를 선별하고 진단하는 데 도움이 되 며, DSM-5에 기반한 국내외 유일한 반구조화된 면담도구라 는 점에서 의의를 갖는다.

\section{Supplementary Materials}

The online-only Data Supplement is available with this article at https:// doi.org/10.13078/jsm.210004.

\section{Acknowledgments}

본 연구는 아모레퍼시픽재단의 학술연구비 지원을 받아 수행되었 음. 연구를 도운 이루다, 한소라, 오하은, 박소영에게 감사의 말씀 전 합니다.

\section{Conflicts of Interest}

The author has no potential conflicts of interest to disclose.

\section{ORCID iD}

Sooyeon Suh https://orcid.org/0000-0003-0644-8634

\section{REFERENCES}

1. Zadra A, Donderi DC. Nightmares and bad dreams: their prevalence and relationship to well-being. J Abnorm Psychol 2000;109:273-281. https://doi.org/10.1037/0021-843X.109.2.273.

2. Spoormaker VI, Schredl M, van den Bout J. Nightmares: from anxiety symptom to sleep disorder. Sleep Med Rev 2006;10:19-31. https://doi. org/10.1016/j.smrv.2005.06.001.

3. American Psychiatric Association. Diagnostic and Statistical Manual of Mental Disorders. 5th ed. Arlington: American Psychiatric Association, 2013;404-407. https://doi.org/10.1176/appi.books.9780890425596.

4. Swart ML, van Schagen AM, Lancee J, van den Bout J. Prevalence of nightmare disorder in psychiatric outpatients. Psychother Psychosom 2013;82:267-268. https://doi.org/10.1159/000343590.

5. Nadorff MR, Nazem S, Fiske A. Insomnia symptoms, nightmares, and suicidal ideation in a college student sample. Sleep 2011;34:93-98. https://doi.org/10.1093/sleep/34.1.93.

6. Spoormaker VI, Verbeek I, van den Bout J, Klip EC. Initial validation of the SLEEP-50 questionnaire. Behav Sleep Med 2005;3:227-246. https:// doi.org/10.1207/s15402010bsm0304_4.

7. Krakow BJ, Melendrez DC, Johnston LG, et al. Sleep Dynamic Therapy for Cerro Grande Fire evacuees with posttraumatic stress symptoms: a preliminary report. J Clin Psychiatry 2002;63:673-684. https://doi. org/10.4088/jcp.v63n0804.

8. Felmingham K, Williams LM, Kemp AH, et al. Neural responses to masked fear faces: sex differences and trauma exposure in posttraumatic stress disorder. J Abnorm Psychol 2010;119:241-247. https://doi. org/10.1037/a0017551.

9. Lee R, Krakow B, Suh S. Psychometric properties of the Disturbing Dream and Nightmare Severity Index-Korean version. J Clin Sleep Med 2021;17:471-477. https://doi.org/10.5664/jcsm.8974.

10. Krakow B, Schrader R, Tandberg D, et al. Nightmare frequency in sexual assault survivors with PTSD. J Anxiety Disord 2002;16:175-190. https://doi.org/10.1016/s0887-6185(02)00093-2.

11. Krakow B, Hollifield M, Schrader R, et al. A controlled study of imagery rehearsal for chronic nightmares in sexual assault survivors with PTSD: a preliminary report. J Trauma Stress 2000;13:589-609. https:// doi.org/10.1023/A:1007854015481.

12. Bastien $\mathrm{CH}$, Vallières A, Morin CM. Validation of the Insomnia Severity Index as an outcome measure for insomnia research. Sleep Med
2001;2:297-307. https://doi.org/10.1016/s1389-9457(00)00065-4.

13. Cho YW, Song ML, Morin CM. Validation of a Korean version of the insomnia severity index. J Clin Neurol 2014;10:210-215. https://doi. org/10.3988/jen.2014.10.3.210.

14. Metalsky GI, Joiner TE. The Hopelessness Depression Symptom Questionnaire. Cogn Ther Res 1997;21:359-384. https://doi.org/10.1023/ A:1021882717784.

15. Suh S, Ryu H, Chu C, Hom M, Rogers ML, Joiner T. Validation of the Korean Depressive Symptom Inventory-Suicidality Subscale. Psychiatry Investig 2017;14:577-584. https://doi.org/10.4306/pi.2017.14.5.577.

16. Radloff LS. The CES-D scale: a self-report depression scale for research in the general population. Appl Psychol Meas 1977;1:385-401. https:// doi.org/10.1177/014662167700100306.

17. Chon KK, Choi SC, Yang BC. Integrated adaptation of CES-D in Korea. Korean J Health Psychol 2001;6:59-76.

18. Spielberger CD, Gorsuch RL, Lushene RE. STAI manual for the statetrait anxiety inventory ("self-evaluation questionnaire"). Palo Alto: Consulting Psychologists Press, 1970.

19. Kim J, Shin D. A study based on the standardization of the STAI for Korea. New Med J 1978;21:69-75.

20. Johns MW. A new method for measuring daytime sleepiness: the Epworth sleepiness scale. Sleep 1991;14:540-545. https://doi.org/10.1093/ sleep/14.6.540.

21. Cho YW, Lee JH, Son HK, Lee SH, Shin C, Johns MW. The reliability and validity of the Korean version of the Epworth sleepiness scale. Sleep Breath 2011;15:377-384. https://doi.org/10.1007/s11325-010-0343-6.

22. Hahn OS, Ahn JH, Song SH, et al. Development of Korean version of structured clinical interview schedule for DSM-IV Axis I disorder: interrater reliability. J Korean Neuropsychiatr Assoc 2000;39:362-372.

23. Weathers FW, Bovin MJ, Lee DJ, et al. The Clinician-Administered PTSD Scale for DSM-5 (CAPS-5): development and initial psychometric evaluation in military veterans. Psychol Assess 2018;30:383-395. https://doi.org/10.1037/pas0000486.

24. Kim WH, Jung YE, Roh D, et al. Reliability and validity of the Korean version of clinician-administered posttraumatic stress disorder scale for DSM-5. J Korean Med Sci 2019;34:e219. https://doi.org/10.3346/ jkms.2019.34.e219.

25. DeVellis RF. Scale development: theory and applications. Los Angeles: SAGE Publication, 2012.

26. Spitzer MB, Robert L, Gibbon M, et al. Structured clinical interview for DSM-IV-TR axis I disorders, research version, non-patient edition (SCIDI/NP). New York: Biometrics Research, New York State Psychiatric Institute, 2002.

27. Cohen J. A coefficient of agreement for nominal scales. Educ Psychol Meas 1960;20:37-46. https://doi.org/10.1177/001316446002000104.

28. McHugh ML. Interrater reliability: the kappa statistic. Biochem Med (Zagreb) 2012;22:276-282. https://doi.org/10.11613/BM.2012.031.

29. Paul F, Schredl M, Alpers GW. Nightmares affect the experience of sleep quality but not sleep architecture: an ambulatory polysomnographic study. Borderline Personal Disord Emot Dysregul 2015;2:3. https://doi.org/10.1186/s40479-014-0023-4.

30. Sjöström N, Hetta J, Waern M. Persistent nightmares are associated with repeat suicide attempt: a prospective study. Psychiatry Res 2009; 170:208-211. https://doi.org/10.1016/j.psychres.2008.09.006.

31. Ma G, Ma K, Zhu Q, et al. Nightmare experience in bipolar I and II disorders. Dreaming 2018;28:33-42. https://doi.org/10.1037/drm0000072.

32. Schredl M, Göritz AS. Stability of nightmare frequency and its relation to neuroticism: a longitudinal study. J Sleep Res 2020;e13126. https:// doi.org/10.1111/jsr.13126.

33. Krakow B. Nightmare complaints in treatment-seeking patients in clinical sleep medicine settings: diagnostic and treatment implications. Sleep 2006;29:1313-1319. https://doi.org/10.1093/sleep/29.10.1313.

34. Lancee J, Spoormaker VI, Van Den Bout J. Nightmare frequency is associated with subjective sleep quality but not with psychopathology. Sleep Biol Rhythms 2010;8:187-193. https://doi.org/10.1111/j.1479- 
8425.2010.00447.x.

35. Nadorff MR, Nazem S, Fiske A. Insomnia symptoms, nightmares, and suicide risk: duration of sleep disturbance matters. Suicide Life Threat Behav 2013;43:139-149. https://doi.org/10.1111/sltb.12003.

36. Lancee J, Schrijnemaekers NC. The association between nightmares and daily distress. Sleep Biol Rhythms 2013;11:14-19. https://doi.org/10.1111/ j.1479-8425.2012.00586.x.

37. Ohayon MM, Shapiro CM. Sleep disturbances and psychiatric disorders associated with posttraumatic stress disorder in the general population. Compr Psychiatry 2000;41:469-478. https://doi.org/10.1053/ comp.2000.16568.

38. Mellman TA, David D, Kulick-Bell R, Hebding J, Nolan B. Sleep disturbance and its relationship to psychiatric morbidity after Hurricane Andrew. Am J Psychiatry 1995;152:1659-1663. https://doi.org/10.1176/ ajp.152.11.1659.

39. van Liempt S, van Zuiden M, Westenberg H, Super A, Vermetten E. Impact of impaired sleep on the development of PTSD symptoms in combat veterans: a prospective longitudinal cohort study. Depress Anxiety 2013;30:469-474. https://doi.org/10.1002/da.22054.
40. Horowitz M, Wilner N, Alvarez W. Impact of Event Scale: a measure of subjective stress. Psychosom Med 1979;41:209-218. https://doi.org/ 10.1097/00006842-197905000-00004.

41. Newell PT, Cartwright RD. Affect and cognition in dreams: a critique of the cognitive role in adaptive dream functioning and support for associative models. Psychiatry 2000;63:34-44. https://doi.org/10.1080/00 332747.2000 .11024892 .

42. Mellman TA, Pigeon WR. Dreams and nightmares in posttraumatic stress disorder. In: Kryger MH, Roth T, Dement WC. Principles and practice of sleep medicine. 4th ed. Philadelphia: W.B. Saunders, 2005; 573-578.

43. Krakow B, Hollifield M, Johnston L, et al. Imagery rehearsal therapy for chronic nightmares in sexual assault survivors with posttraumatic stress disorder: a randomized controlled trial. JAMA 2001;286:537545. https://doi.org/10.1001/jama.286.5.537.

44. Spoormaker VI, Montgomery P. Disturbed sleep in post-traumatic stress disorder: secondary symptom or core feature? Sleep Med Rev 2008;12:169-184. https://doi.org/10.1016/j.smrv.2007.08.008. 